\title{
Basics of Anesthesia, 6th Edition
}

\author{
Ronald D. Miller, Manuel Pardo. Elsevier Saunders, Philadelphia, \\ United States; 832 pages, 2011. ISBN: 978-1-4377-1614-6
}

\author{
Alim Punja, MD
}

Published online: 24 August 2011

(C) Canadian Anesthesiologists' Society 2011

This sixth edition of Basics of Anesthesia, a core textbook related to the specialty of anesthesiology, proves to be a reasonable improvement on the previous edition. Although some readers will bemoan the fact that the former editor, Robert K. Stoelting, did not edit this current edition, his successor, Manuel C. Pardo Jr, and the 30-plus new expert contributors maintain the concise reader-friendly character of the previous editions. Compared with the previous editions which centred at the University of California, San Francisco (UCSF), the new contributors represent a plurality of American institutions and their practices.

The text is divided into six sections, with Section I focused on the history and scope of the practice of anesthesia. The five remaining sections, "Pharmacology and Physiology", "Preoperative Preparation and Intraoperative Management", "Special Anesthetic Considerations", "Recovery Period", and "Consultant Anesthetic Practice" are expanded to touch on various subspecialty considerations and major comorbid conditions. In addition, there are three new chapters in this edition: "Anesthesia for Orthopedic Surgery", "Awareness under Anesthesia", and "Quality of Care and Patient Safety". Each chapter in the text is organized in a manner pertinent to its specific content area; they follow one another logically and, despite the number of contributors, there is an internal consistency throughout the chapters with little overlap of content among them.
As with previous editions, this sixth edition is published in full colour, a feature that most readers will find engaging. Many tables and diagrams enhance the straightforward and clear text, and they present important key concepts and strategies without overwhelming the reader. This simplicity in presentation and style makes this text ideal, particularly for residents early in their training. Although the authors' goal is to provide a text that serves as a resource for an entire spectrum of learners up to fellowship level, the more senior learners will find themselves desperate for additional detail not present in this book.

The full text is available on-line via "Expert Consult" (www.expertconsult.com/) with the provided code from any computer; however, there is no additional web-based content.

In a crowded textbook market, this latest edition of Basics of Anesthesia has its niche with junior learners and is exceptional in this area. The text will serve as a valuable resource for those early in their residency training and as a general refresher reference text for practicing family physician anesthesiologists. Those involved in resident education may also benefit from referring to this text to provide a framework for teaching the basic elements of clinical anesthesia.

Competing interests None declared.

A. Punja, MD ( $\square)$

University of Ottawa, Ottawa, Canada

e-mail: apunja@toh.on.ca 